\title{
Micropropagation and Simultaneous Rooting of Actinidia deliciosa var. deliciosa 'Hayward'
}

\author{
M. Cristina Pedroso, M. Margarida Oliveira, and \\ M. Salomé S. Pais \\ Departament Biologia Vegetal, Faculdade Ciências de Lisboa, Bloco C2, \\ Campo Grande, Lisbon 1700, Portugal
}

Additional index words in vitro propagation, kiwifruit

\begin{abstract}
Nodal segments and shoot tips of axenic shoot cultures of 'Hayward' kiwifruit were inoculated on modified Murashige and Skoog (MS) medium supplemented with zeatin at $1 \mathrm{mg}^{-1 i t e r}{ }^{-1}$ and IAA at $0.05 \mathrm{mg}^{-1 i t e r}{ }^{-1}$ (H1) or on MS medium without growth regulators $(\mathrm{H2})$. Inocula cultured on $\mathrm{H} 2$ medium all developed into normal plantlets, while those cultured on $\mathrm{H1}$ medium developed into shoots, $18 \%$ of them abnormal. Rooting of $\mathrm{H1}$ shoots was induced by a 24-h immersion in a solution of IRA at $20 \mathrm{mg} \cdot \mathrm{liter}^{-1}$. $\mathrm{H} 2$ plantlets were directly transferred to soil. Statistical treatment of the results revealed no significant differences, in terms of plant development, between the two micropropagation methods used. However, the presence of a functional root system on 5-week-old $\mathrm{H} 2$ plantlets resulted in $100 \%$ plant survival, but only $70 \%$ of in vivo-rooted shoots from $\mathrm{H1}$ survived. Nevertheless, H1 still allowed for an important reduction of costs and manipulation. Chemical names used: indole3-acetic acid (IAA).
\end{abstract}

Kiwifruit is a woody species traditionally considered to be resistant to disease. However, several pathogens have already been found that cause severe damage in kiwifruit orchards. Fungi and bacteria, in particular, are problems with the traditional propagation methods of slips or grafts (Zuccherelli and Zuccherelli, 1981).

Micropropagation has been proposed as a way to avoid some of the problems with the vegetative propagation of Actinidia deliciosa (Aldrufeu et al., 1985; Gautheret, 1980; Harada, 1975; Kwei et al., 1978; Pais et al., 1987; Rodriguez et al., 1985). The increasing demand for kiwifruit led us to improve the method used for the micropropagation of this plant, to reduce callus production and obtain stronger roots, making the acclimatization step easier. We present an easy and quick method for the propagation and acclimatization of kiwifruit, which we have been using in our laboratory for the last 3 years.

Axillary buds, obtained from selected fieldgrown plants of 'Hayward' kiwifruit, were micropropagated on $\mathrm{H}$ medium (Pais et al., 1987 ) and shoots were maintained for 2 years in our laboratory. All experiments were performed using nodal segments and shoot tips (3:1 ratio) from these shoots. Two micropropagation methods were tested using two variations of $\mathrm{H}$ medium, each one containing dithiothreitol (DTT) as anti-oxidant at 5 mg.liter ${ }^{-1}$. H1 medium, supplemented with zeatin at $1 \mathrm{mg} \cdot \operatorname{liter}^{-1}$ and IAA at 0.05

Received for publication 7 Mar. 1991. Accented for publication 9 Dec. 1991. We thank Lucinda Oliveira das Neves, for help with the statistical analysis of data. The cost of publishing this paper was defrayed in part by the payment of page charges. Under postal regulations, this paper therefore must be hereby marked advertisement solely to indicate this fact. $\mathrm{mg} \cdot \mathrm{liter}^{-1}$, was followed by a $24-\mathrm{h}$ immersion in a sterile solution of IBA at 20 $\mathrm{mg} \cdot \mathrm{liter}^{-1}$ for induction of in vivo rooting (Pais et al., 1987). Culture on H2 medium (H1 without growth regulators) was followed by directly potting the plantlets obtained. Cultures were grown at $22 \pm 2 \mathrm{C}$ under coolwhite fluorescent lights $\left(26 \mu \mathrm{mol} \cdot \mathrm{m}^{-2} \cdot \mathrm{s}^{-1}\right)$ with a 16 -h photoperiod. When shoots were transferred to soil (5 and 8 weeks after culture initiation), the following characteristics were evaluated: stem length, number of buds per inoculated bud and per plantlet, presence or absence of basal callus, percentage of shoots that rooted, number of root primordia per shoot, number of roots per plantlet, longest root length, shoot fresh weight, frequency of death, and aberrant forms. In each experiment 40 explants were used per culture medium tested ( $\mathrm{H} 1$ or $\mathrm{H} 2$ ), and the experiments were repeated 14 times over 2 years. Plants were potted on 0.160-liter pots containing a 1 sand : 1 soil mixture (v/v). The plants were kept in the nursery for 30 days at $80 \%$ relative humidity with a 16 -h photoperiod under reduced light (8.6 $\left.\mu \mathrm{mol} \cdot \mathrm{m}^{-2} \cdot \mathrm{s}^{-1}\right)$. Twenty plants were tested for each rooting method and examined 2 and 4 weeks after potting. This experiment was repeated eight times from January to September. All data were analyzed by Tukey HSD test at $\alpha=0.05$.

Micropropagation. Five weeks after culture initiation, $81 \%$ of the explants on $\mathrm{H} 1$ medium and $93 \%$ on $\mathrm{H} 2$ had survived. Shoots regenerating on $\mathrm{H} 1$ developed a basal callus and had no roots, and $18 \%$ of them displayed aberrant forms. Those regenerating on $\mathrm{H} 2$ had no basal callus, developed 1.8 roots per shoot, and all were normal.

The roots that began to appear during the 2nd to 3rd weeks of culture on shoots regenerating on $\mathrm{H} 2$ medium were thick and covered with root hairs, and $24 \%$ of them developed lateral roots (mean of 2.6 per shoot). Increasing the subculture period of $\mathrm{H} 2$ plantlets from 5 to 8 weeks significantly increased thickness and length of roots, increased the percentage of roots with laterals from $24 \%$ to $64 \%$, and increased the number of lateral roots per root from 2.6 to 7.0.

Increasing the subculture period of $\mathrm{H} 1$ shoots from 5 to 8 weeks increased root formation from $0 \%$ to $6.7 \%$. However, these roots were thin, long, without hairs, and not functional. Repeated subcultures of $\mathrm{H} 1$ shoots at 5-week intervals led to a decrease of callus weight and, at the 14th subculture, to an increase in aberrant forms from $19 \%$ to $28 \%$. When $\mathrm{H} 2$ medium was used, repeated subcultures did not affect plantlet survival or promote the development of aberrant forms. At the time of potting, $\mathrm{H} 2$ plantlets tended to have longer stems, more buds, and higher shoot fresh weights than shoots from $\mathrm{H} 1$, although differences were not significant (Fig. 1; Table 1).

Potting. During the first 2 weeks of potting, 5-week-old H1 in vivo-rooted shoots produced significantly more root primordia and roots per plantlet than the controls ( $\mathrm{Ta}$ ble 1). During this period of no visible growth, one to three leaves per shoot became necrotic. Four weeks after potting (9 weeks total) significant increases of stem length $(P<0.002)$ (not followed by an increase of buds per plantlet), plantlet fresh weight $(P<0.002)$, roots per plantlet $(P<0.001)$, and length of the longest $\operatorname{root}(P<0.001)$ were observed. Plantlet survival was only $70 \%$; absence of root development in soil accounted for the loss of $30 \%$ of the potted shoots. Between the 2nd and 4th weeks of potting, 8-week-old H1 shoots increased in stem length and fresh weight, but slightly less so than the 5-week-old H1 shoots. The increase of the subculture period from 5 to 8 weeks increased $\mathrm{H} 1$ plant survival and rooting by $13 \%$, but no significant increase in growth was observed by 4 weeks after potting.

Five-week-old $\mathrm{H} 2$ plantlets had increased significantly in stem length $(P<0.001)$ during the first 2 weeks of potting. Four weeks after potting, all 5-week-old H2 plantlets had survived, and there was a significant increase in stem length $(P<0.002)$, number of roots per plantlet $(P<0.001)$, length of

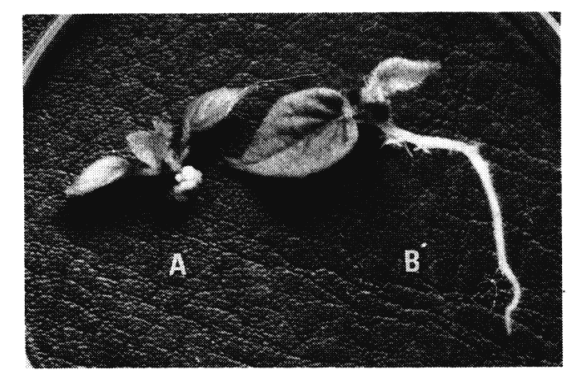

Fig. 1. Five-week-old kiwifruit plantlets grown on medium with growth regulators (H1) (A) and without growth regulators $(\mathrm{H} 2)(B)$, at the time of transfer to soil ( $\times 0.89$ magnification). 


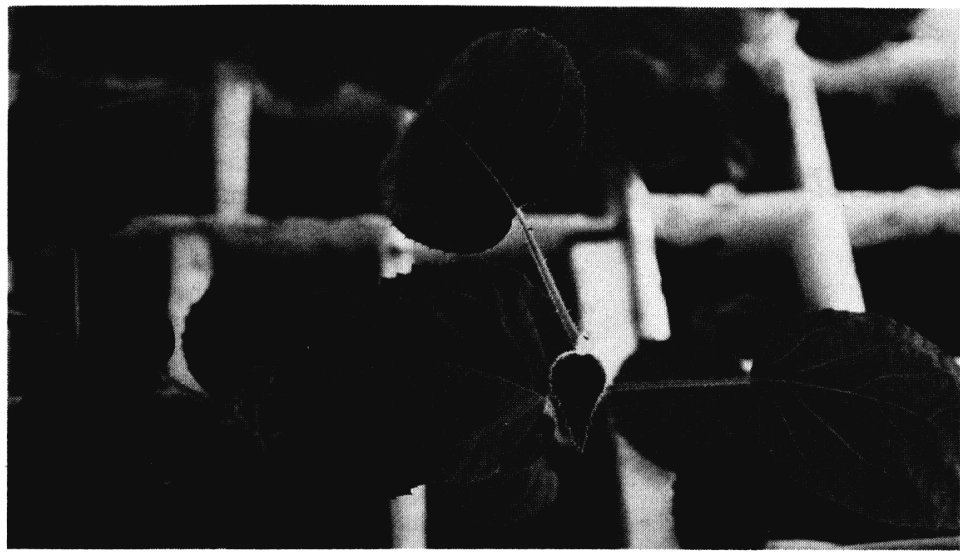

Fig. 2. Vigorous $\mathrm{H} 2$ plants after 2 months of growth in soil ( $\times 0.38$ magnification).

Table 1. Comparison of 5- and 8-week-old $\mathrm{H} 2$ kiwifruit plantlets and 5- and 8-week-old $\mathrm{H} 1$ shoots rooted in vivo. The values (per $\mathrm{H} 2$ plantlet or $\mathrm{H} 1$ in vivo-rooted shoot) were calculated at potting and 2 and 4 weeks after potting. Column values not followed by the same letter are significantly different by Tukey HSD test at $\alpha=0.05$.

\begin{tabular}{|c|c|c|c|c|c|c|c|c|}
\hline \multirow[b]{2}{*}{ Medium } & \multirow[b]{2}{*}{$\begin{array}{l}\text { Weeks } \\
\text { in vitro }\end{array}$} & \multirow[b]{2}{*}{$\begin{array}{c}\text { Weeks after } \\
\text { potting }\end{array}$} & \multirow[b]{2}{*}{$\begin{array}{c}\text { Stem length } \\
(\mathrm{mm})\end{array}$} & \multicolumn{3}{|c|}{ No./plantlet } & \multirow[b]{2}{*}{$\begin{array}{l}\text { Longest root } \\
\text { (mm) }\end{array}$} & \multirow{2}{*}{$\begin{array}{l}\text { Plantlet } \\
\text { fresh wt } \\
\text { (g) }\end{array}$} \\
\hline & & & & Buds & $\begin{array}{c}\text { Root } \\
\text { primordia }\end{array}$ & Roots & & \\
\hline H1 & 5 & $\begin{array}{l}0 \\
2 \\
4 \\
0 \\
2 \\
4\end{array}$ & $\begin{array}{c}5.3 \mathrm{a} \\
10.9 \mathrm{ab} \\
19.8 \mathrm{~cd} \\
8.2 \mathrm{ab} \\
15.3 \mathrm{abd} \\
17.4 \mathrm{~d}\end{array}$ & $\begin{array}{l}3.6 \mathrm{a} \\
3.6 \mathrm{a} \\
4.5 \mathrm{ac} \\
4.4 \mathrm{a} \\
4.4 \mathrm{ab} \\
4.8 \mathrm{ab}\end{array}$ & $\begin{array}{l}0.0 \\
3.5 \mathrm{~b} \\
0.5 \mathrm{a} \\
0.0 \\
2.3 \mathrm{~b} \\
0.4 \mathrm{ac}\end{array}$ & $\begin{array}{l}0.0 \\
0.7 \mathrm{ce} \\
3.8 \mathrm{bf} \\
0.0 \\
0.3 \mathrm{de} \\
2.6 \mathrm{af}\end{array}$ & $\begin{array}{c}0.0 \\
10.5 \mathrm{~d} \\
43.7 \mathrm{ac} \\
0.0 \\
11.8 \mathrm{~d} \\
46.7 \mathrm{ce}\end{array}$ & $\begin{array}{l}0.17 \mathrm{a} \\
0.27 \mathrm{ab} \\
0.58 \mathrm{~cd} \\
0.20 \mathrm{a} \\
0.49 \mathrm{bce} \\
0.72 \mathrm{cfg}\end{array}$ \\
\hline $\mathrm{H} 2$ & 8 & $\begin{array}{l}0 \\
2 \\
4 \\
0 \\
2 \\
4\end{array}$ & $\begin{array}{l}6.7 \mathrm{a} \\
15.8 \mathrm{bd} \\
24.8 \mathrm{c} \\
11.8 \mathrm{ab} \\
16.8 \mathrm{abd} \\
25.0 \mathrm{c}\end{array}$ & $\begin{array}{l}4.6 \mathrm{ab} \\
5.2 \mathrm{~b} \\
5.7 \mathrm{bc} \\
4.7 \mathrm{ab} \\
5.0 \mathrm{ab} \\
5.2 \mathrm{ab}\end{array}$ & $\begin{array}{l}0.1 \mathrm{a} \\
0.4 \mathrm{a} \\
0.4 \mathrm{a} \\
0.1 \mathrm{a} \\
0.6 \mathrm{a} \\
0.4 \mathrm{a}\end{array}$ & $\begin{array}{l}1.8 \mathrm{a} \\
2.3 \mathrm{a} \\
4.2 \mathrm{~b} \\
1.4 \mathrm{ac} \\
1.6 \mathrm{~cd} \\
2.3 \mathrm{a}\end{array}$ & $\begin{array}{l}30.4 \mathrm{a} \\
37.3 \mathrm{ac} \\
62.7 \mathrm{~b} \\
37.2 \mathrm{ae} \\
46.6 \mathrm{ce} \\
73.0 \mathrm{~b} \\
\end{array}$ & $\begin{array}{l}0.29 \text { abe } \\
0.34 \text { ade } \\
0.59 \text { dg } \\
0.35 \text { ade } \\
0.50 \text { bd } \\
0.97 \text { f } \\
\end{array}$ \\
\hline
\end{tabular}

${ }^{\mathrm{z}} \mathrm{H} 1$ with and $\mathrm{H} 2$ without growth regulators.

the longest root $(P<0.001)$, root thickness $(\approx 85 \%)$, leaf area, and number of lateral roots per root (data not shown). These plants exhibited more vigorous growth throughout acclimatization and in soil (Pig. 2) than did $\mathrm{H} 1$ plants rooted in vivo. The increase of the subculture period from 5 to 8 weeks significantly increased the fresh weight of $\mathrm{H} 2$ plantlets $(P<0.001)$ but significantly decreased the number of roots per plantlet and decreased plantlet survival from $100 \%$ to $94 \%$. Comparison of the other characteristics did not reveal significant differences between 5and 8-week-old $\mathrm{H} 2$ plantlets (Table 1).

The total loss of plant material during micropropagation and potting using a 5-week subculture period was significantly lower for $\mathrm{H} 2$ plantlets (7\%) when compared with $\mathrm{H} 1$ shoots $(49 \%)$.

The antioxidant DTT was used in both culture media tested instead of ascorbic acid (Pais et al., 1987) because of DTT's beneficial effect on increasing the percentage of bud survival (22\%) and increasing the number of buds per inoculated bud (1.8) (unpublished results). By favoring reducing conditions and inhibiting oxidations, DTT has a positive effect on cell division and rejuvenation, relative to maturation and senescence (Stonier and Yang, 1981).
The presence of a basal callus, the absence of roots, and the development of aberrant forms after repeated subculturing, as observed on $\mathrm{H} 1$ cultures, were also reported by others who used different media than we used but that contained growth regulators (Rodriguez et al., 1985). According to these authors, these responses may be due to the use of axillary buds and nodal segments as primary explants. Based on our results, we believe that the absence of aberrant forms on $\mathrm{H} 2$ medium and their presence on $\mathrm{H} 1$ medium cannot be explained by the type of explant used, because it was identical on both media tested. The difference may be due to the use of growth regulators in $\mathrm{H} 1$ medium.

A 5-week subculture period proved to be the most appropriate. Longer periods, although promoting root formation on $\mathrm{H} 1$ shoots while still in culture, had no significant overall effect on rooting, plant growth, or survival. However, on $\mathrm{H} 2$ cultures, increased subculture period resulted, 4 weeks after potting, in a reduction of plant survival and number of roots per plantlet.

Rooting of kiwifruit shoots usually has been achieved by soaking or immersion in an IBA solution followed by culture on a rooting medium or by direct potting (Aldrufeu et al., 1985; Barbieri and Morini, 1987; Harada,
1975; Monette, 1987; Pais et al., 1987; Revilla and Power, 1988; Rodriguez et al., 1985; Velayandom et al., 1985). The in vitro formation of hairless thin roots that died shortly after potting, as observed on H1 medium, has been reported previously and is considered a disadvantage of in vitro rooting of $A$. chinesis shoots (Aldrufeu et al., 1985). The development of $\mathrm{H} 2$ plantlets with a functional root system led to easier and faster adaptation to potting and a significant increase in stem length and root thickness just 2 weeks after potting. This procedure also was found to be highly efficient for shoots regenerated from protoplast cultures (Oliveira and Pais, 1991). The culture methods reported until now required 11 to 13 weeks for total plant recovery (Aldrufeu et al., 1985; Harada, 1975; Pais et al., 1987; Rodriguez et al., 1985). Using $\mathrm{H} 2$ medium and the described culture conditions, total plant recovery was achieved in only 9 weeks. Moreover, the simultaneous in vitro formation of a functional root system with plantlet production allows an important reduction of manipulation and of growth regulator costs. High plant survival (93\%) after the entire process (micropropagation + potting) and the effect of repeated subcultures on the increase of rooting potential and growth after potting also seem to be advantages when compared with the previously reported procedures.

\section{Literature Cited}

Aldrufeu, A., N. Cols, and J. Adillon. 1985. Aplicacion de la tecnica de cultivo in vitro a la multiplicacion de 1a Actinidia chinensis Planch. Porencias Y Comunicaciones das Primeras Jornadas Técnicas sobre Actinidia (kiwi), Vigo (Pontevedra) Spain, 17-19 Oct. 1985. p. 119125.

Barbieri, C. and S. Morini. 1987. Plant regeneration from Actinidia callus cultures. J. Hort. Sci. 62:107-109.

Gautheret, R. 1980. Sur la multiplication végétative de 1' Actinidia chinensis Planch. "Chinese gooseberry", par culture de racines issues de filets staminaux. C.R. Acad. Sci. Paris 291:1067-1069.

Harada, H. 1975. In vitro organ culture. of Actinidia chinensis $\mathrm{Pl}$. as a technique for vegetative multiplication. J. Hort. Sci. 50:81-83.

Kwei, Y.-L., H.-H. An, T.-R. Tsai, and J.-R. Wang. 1978. Induction of callus and plantlet from stem segment in Chinese gooseberry. Proc. Symp. Plant Tissue Cult., Peking, China, 2530 May 1978. Science Press, Peking. p. 526.

Monette, P.L. 1987. Organogenesis and plantlet regeneration following in vitro cold storage of kiwifruit shoot tip cultures. Scientia Hort. 31:101-106.

Oliveira, M.M. and M.S. Pais. 1991. Plant regeneration from protoplasts of long-term callus cultures of Actinidia deliciosa var. deliciosa cv. Hayward (kiwifruit). Plant Cell Rptr. 9:643646.

Pais, M.S., M.M. Oliveira, and J. Barroso. 1987. Use of petiole segments of Actinidia chinensis (Kiwi) for plant differentiation and production of friable calli for protoplast isolation. Acta Hort. 212:687-690.

Revilla, M.A. and J.B. Power. 1988. Morphogenetic potential of long-term callus cultures of Actinidia deliciosa. J. Hort. Sci. 63:541-545. 
Rodriguez, R., A. Vasquez, R. Ordas, and B. Fernandez. 1985. Topofisis y micropropagation de l'Actinidia deliciosa. Porencias Y Comunicaciones das Primeras Jornadas Técnicas sobre Actinidia (kiwi), Vigo (Pontevedra) Spain, 1719 Oct. 1985. p. 127-130.
Stonier, T. and H.-M. Yiang. 1971. Studies on auxin protectors $\mathrm{X}$. Protector levels and lignification in sunflower crown gall tissue. Physiol. Plant. 25:474-481.

Velayandom, L., A.M. Hirsch, and D. Fortune. 1985. Propagation du kiwi Actinidia chinensis
(L.) Planchon, par microbouturage in vitro de noeuds. C. Hebd. Seances Acad. Sci. (III), Paris 301:597-600.

Zuccherelli, G. and G. Zuccherelli. 1981. L'Actinidia. Pianta da fruto e da giardino. Edagricole, Bologna, Italy. 